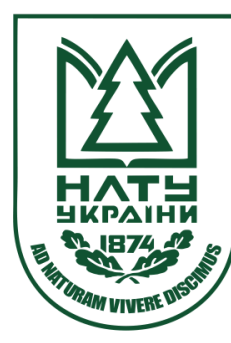

Науковий вісник НлтУ України

Scientific Bulletin of UNFU

https://nv.nltu.edu.ua

https://doi.org/10.36930/40310216

$@ \bowtie$ Correspondence author

Article received 09.04.2021 p.

Article accepted 29.04.2021 p.

B. O. Lysko

UDC 528.3

Б. О. Лиско, В. П. Михайлишин

Івано-Франківський національний технічний університет нафти і газу, м. Івано-Франківськ, Україна

\title{
ВИЗНАЧЕННЯ ПОСТІЙНОЇ ПОПРАВКИ ЕЛЕКТРОННИХ ВІДДАЛЕМІРІВ МЕТОДАМИ НЕЛІНІЙНОГО ПРОГРАМУВАННЯ
}

Розроблено алгоритм опрацювання результатів досліджень постійної поправки електронних тахеометрів. Його суть полягає у використанні методу Гауса та знаходженні мінімуму деякої функції визначення похибок виміряних віддалей. Спочатку було досліджено кількість необхідних вимірювань для приладу: розглянуто вплив кореляційної залежності між величинами інструментальної і випадкової похибок. Далі складено систему рівнянь на підставі залежностей між довжиною виміряного створу та його відрізків у всіх комбінаціях з урахуванням постійної поправки віддалеміра. Отже, отримано умовні рівняння $з$ однією невідомою - постійною поправкою віддалеміра. За наявністю великої кількості вимірювань розв'язання такої системи рівнянь полягає у знаходженні мінімуму деякої функції визначення похибок виміряних віддалей. При цьому найдоцільнішим вибором $є$ критерій мінімізації максимального відхилення, який дає змогу відбракувати грубі помилки у виміряних значеннях. Отже, отримано найімовірніше значення постійної поправки віддалеміра, значення довжин виміряного створу та його відрізків, які будуть узгодженими у всіх можливих комбінаціях. Дослідження здійснено на геодезичному полігоні за оптимальних метеорологічних умов. З'ясовано, що запропоновані технологічні рішення можуть підвищити точність урівноваження значення постійної поправки віддалеміра, довжин виміряного створу та його відрізків, порівняно із відомим методом корелат, мінімум на 10 \%. На прикладі дослідження тахеометра SOUTH NTS-350 встановлено, що точність отриманих апроксимованих значень довжин створу і його відрізків практично у три рази вища від задекларованої у технічних характеристиках СКП вимірювання довжин ліній цим самим приладом.

Ключові слова: електронний тахеометр; похибки вимірювань; мінімізація квадратів відхилень; теорія похибок; рівноточні виміри.

\section{Вступ}

На сьогодні віддалемірна техніка, а саме електронні тахеометри, широко застосовують практично у всіх видах геодезичних робіт та різноманітних дослідженнях $[5,8]$. Однією зі сфер застосування електронних тахеометрів є моніторинг деформацій інженерних споруд, які потребують періодичного контролю геометричних параметрів. Дані задачі складні для розв'язання і потребують високої точності виконання вимірювання [7, 13]. Для забезпечення необхідної точності результатів вимірювань потрібно мінімізувати вплив систематичних похибок, які можуть виникати через різні чинники, зокрема незбіг осей обертання електронного віддалеміра i відбивача $[12,14]$. У більшості сучасних електронних тахеометрів ця постійна поправка $(v)$ встановлена такою, що дорівнює нулю [10]. Однак унаслідок експлуатації приладу іiі значення із часом може змінюватись. Тому для забезпечення високої точності та отримання надійних результатів у роботі з електронним тахеометром цю систематичну похибку необхідно враховувати. Класично визначення постійної поправки електронних віддалемірів виконують на еталонних геодезичних полігонах $[9,10,15]$, порівнюючи вимірювані значення тензорних величин із їх еталонними значеннями. Однак сьогодні на території України недостатньо еталонних геодезичних полігонів та метрологічних лабораторій, щоб забезпечити швидкий та якісний контроль віддалемірної техніки. Усе це обгрунтовує необхідність удосконалення наявних та розроблення нових методик визначення постійної поправки електронних тахеометрів.

Об'єкт дослідження - високоточне вимірювання та моніторинг лінійних інженерних споруд у реальних атмосферних умовах.

Предмет дослідження - методи і технологічні рішення визначення постійної поправки електронних тахеометрів із застосуванням сучасних геодезичних способів.

Мета роботи - розроблення нової методики опрацювання результатів досліджень при обчисленні постійної поправки електронної віддалемірної техніки з використанням методів нелінійного програмування.

Для досягнення зазначеної мети визначено такі основні завдання дослідження:

1) розробити рекомендації 3 підвищення точності та ефективності виконання досліджень 3 визначення постійної поправки електронних тахеометрів, завдяки забезпеченню оптимальної кількості вимірів;

\section{Інформація про авторів:}

Лиско Богдан Олегович, канд. техн. наук, асистент, кафедра геодезії та землеустрою. Email: 93lisko@gmail.com; https://orcid.org/0000-0002-2525-1557

Михайлишин Володимир Петрович, завідувач лабораторії, кафедра геодезії та землеустрою. Email: 93lisko@gmail.com

Цитування за ДСтУ: Лиско Б. О., Михайлишин В. П. Визначення постійної поправки електронних віддалемірів методами нелінійного програмування. Науковий вісник НЛтУ України. 2021, т. 31, № 2. С. 98-102.

Citation APA: Lysko, B. O., \& Mykhailyshyn, V. P. (2021). Determination of constant correction of electronic rangefinders by nonlinear programming methods. Scientific Bulletin of UNFU, 31(2), 98-102. https://doi.org/10.36930/40310216 
2) розробити методику розрахунку постійної поправки електронних тахеометрів методами нелінійного програмування $з$ можливістю відбракування грубих похибок;

3) апробувати запропоновані технологічні рішення на проммайданчику.

Наукова новизна отриманих результатів дослідження - вперше запропоновано використовувати метод узагальненого зведеного градієнта (GRG) 3 послідовним використанням критеріїв мінімізації максимального відхилення та мінімізації повної суми квадратів відхилень для визначення постійної поправки віддалеміра, що дало змогу підвищити точність й ефективність отриманих результатів.

Практична значущість результатів дослідження:

1) можливість проводити метрологічний контроль тахеометрів практично на проммайданчику перед виконанням високоточних інженерно-геодезичних робіт;

2) зменшення часу виконання віддалемірних вимірювань за допомогою визначення оптимальної кількості необхідних вимірювань для приладу;

3) підвищення точності визначення постійної поправки віддалеміра мінімум на 10 \% порівняно із відомим методом корелат.

Аналіз останніх досліджень та публікацій. На сьогодні відомо декілька $[1,2]$ класичних методів визначення постійної поправки шляхом вимірювання відомої віддалі на еталонному геодезичному базисі. У першому варіанті [11] виконується вимірювання еталонного базису завдовжки 300-500 м, у другому [13] вимірюються віддалі відомої довжини в межах фазового циклу, у третьому вимірюється декілька базисів, довжини яких були виміряні іншим повіреним приладом із необхідною точністю [10]. У цих методиках постійна поправка електронного тахеометра розраховується як різниця між відомою віддаллю та виміряною за допомогою досліджуваного електронного тахеометра. Недоліком описаних вище методів є необхідність проведення досліджень на еталонному геодезичному базисі, точність якого повинна становити $2 \cdot 10^{-6} \mathrm{M}$, вплив похибок центрування тахеометра та відбивача, дестабілізаційні чинники, такі як атмосферні умови.

Проте неподалік місця проведення високоточних інженерно-геодезичних робіт еталонного базису може не бути, а створення такого полігону за короткий термін $\epsilon$ неможливим. Відомо, що кількість еталонних геодезичних полігонів в Україні є недостатня $[17,18]$. Такі полігони функціонують у Києві, Харкові, Вінниці, Криму, Миколаєві, Львівській області [15] та на території Коломийського аеропорту в Івано-Франківській області (свідоцтво про державну метрологічну атестацію ДП "Укрметртестстандарт" №23-0054 від 28.05.2015 р.). Альтернативою цим способам можна вважати методики, які базуються на виконанні лінійно- кутових вимірювань [4]. Перевагами цих методів є висока точність отриманих результатів та можливість виконання вимірювань безпосередньо на об'єкті робіт, проте на етапі опрацювання результатів у такій мережі є складності із вибором вагових коефіцієнтів для лінійних вимірів та кутових вимірів. На нашу думку, найефективнішим та простим у реалізації $є$ вимірювання відрізків створу у всіх комбінаціях $[12,3]$. Основними перевагами цього способу є простота реалізації, відсутність потреби у додатковому обладнанні та швидкість виконання. Рекомендацій щодо опрацювання результатів такого дослідження немає.

\section{Результати дослідження та їх обговорення}

Оскільки всі результати вимірювань однорідні, отримані одним і тим самим приладом та методом вимірювань за однакових метеорологічних умов, то приймемо, що всі отримані значення рівноточні. Отже, загальну похибку вимірювання $(\delta)$ можна подати як суму систематичної $(v)$ та випадкової складових $(\Delta)$ :

$$
\delta=v+\Delta .
$$

Для підвищення точності отриманих результатів, необхідно виключити випадкову складову похибки приладу із результатів виміряних віддалей. Враховуючи властивість компенсації рівноточних похибок, та властивість простої арифметичної середини, можна стверджувати, що арифметична середина буде вільна від випадкових похибок. Ці умови дають змогу записати

$$
\Delta_{i}=S_{i}-\frac{\left[S_{i}\right]}{n}-v .
$$

На практиці ж кількість вимірів є обмеженою, тому для отримання достовірних результатів необхідно перевіряти чи отримані значення підпорядковуються нормальному закону розподілу, для якого функція густини розподілу випадкових величин виражається формулою

$$
\Phi(X)=\frac{1}{\sigma \sqrt{2 \pi}} \exp ^{-\frac{m}{2 \sigma^{2}}},
$$

де: $m$ - математичне сподівання; $\sigma$ - середнє квадратичне відхилення ( $\sigma^{2}-$ дисперсія).

Згідно з теорією похибок, якщо випадкові похибки, отримані із рівноточних вимірювань, підкоряються нормальному закону розподілу Гауса, то на них діють описані вище властивості. Використання апарату математичної статистики є складним, тому альтернативою використання функції густини розподілу випадкових величин можна використовувати правило $3 \sigma$ :

$$
P(|X-a| \geq 3 \sigma) \rightarrow 0 .
$$

Правило $3 \sigma$ доцільно використати для перевірки отриманих вимірів на відповідність підпорядкуванню нормальному закону розподілу: якщо закон розподілу виміряних значень невідомий, але умова, вказана в цьому правилі, виконується, тоді можна припустити, що випадкова величина розподілена нормально. Імовірність того, що відхилення за абсолютною величиною буде менше від потроєного середнього квадратичного відхилення, дорівнює 0,9973.

Теорія методу Гауса показує, що нескінченне збільшення числа вимірювань не дає помітного збільшення точності $[6,16]$. Тому не доцільно, а інколи і неможливо, виконувати велику кількість вимірювань для визначення однієї величини, у нашому випадку - віддалі. Кількість необхідних вимірювань визначається співвідношенням величини інструментальної (для електронного тахеометра SOUTH NTS-350 $m=2$ мм +2 мм на 1 км) і випадкової похибок $(\Delta)$.

У такому випадку зберігається ефективність мінімізації квадратів відхилень. Для визначення стандартного відхилення використаємо відому формулу

$$
\sigma(\hat{\delta})=\frac{1}{n} \sqrt{\sum_{i=1}^{n} D_{i, j}}
$$

де $D_{i, j}$ - коваріаційна матриця похибок вимірювань, що визначається за формулою 


$$
D_{i, j}=\left\{\begin{array}{l}
\sigma^{2} \text { при } i=j \\
k \sigma^{2} \text { при } i \neq j .
\end{array}\right.
$$

Для визначення оптимальної кількості вимірювань однієї величини розглянемо вплив кореляційної залежності між похибками вимірювань. Унаслідок вимірювань отримано 200 рівноточних вимірів та обчислено їх середньоквадратичні похибки $(\sigma)$. Розрахуємо кореляційну залежність між похибками вимірювання, сталий коефіцієнт кореляції становить $k=0,8834$.

На рис. 1 зображено графік залежності співвідношення від кількості $n$ вимірювань.

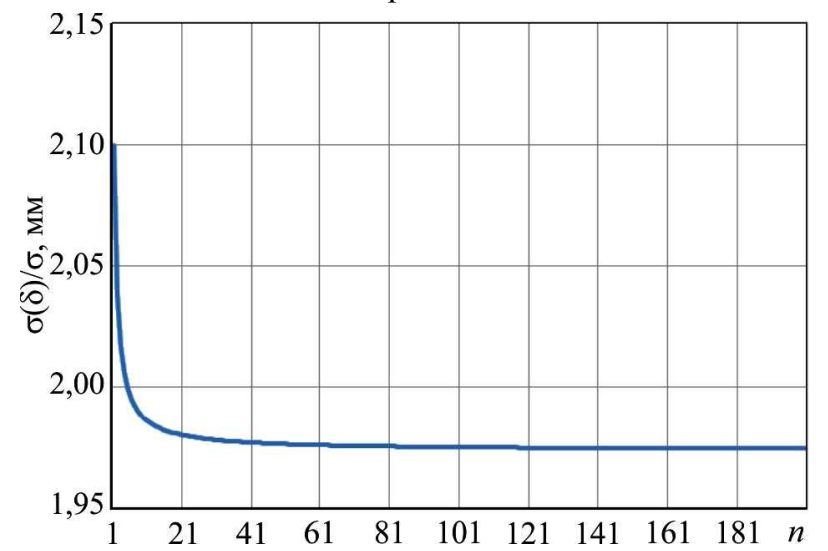

Рис. 1. Залежність стандартного відхилення за середнім арифметичним від числа вимірювань

Із рис. 1 видно, що із збільшенням кількості $n$ кількості вимірювань розглянута функція приймає менші значення, наближаючись до свого мінімуму. Однак, починаючи із деякої кількості вимірів ( $n=40)$, зменшення похибки стає незначущим та надалі збільшення кількості виконаних вимірів можна вважати практично не виправданим. Для детальнішої оцінки отриманої вибірки дослідимо вплив не врахованої кореляції між вимірами на оцінку точності.

Розрахуємо середньоквадратичну похибку за формулою Бесселя, щоб надалі мінімізувати вплив систематичних похибок:

$$
\hat{\sigma}=\sqrt{\frac{\sum_{n=1}^{n}\left(S_{i}-S_{c e p}\right)}{n-1}} .
$$

Отримавши значення СКП для різної кількості вимірювань у діапазоні однієї вибірки, що складається із 40 рівноточних вимірів віддалі, графічно зобразимо вплив не врахованої кореляції для цього випадку.

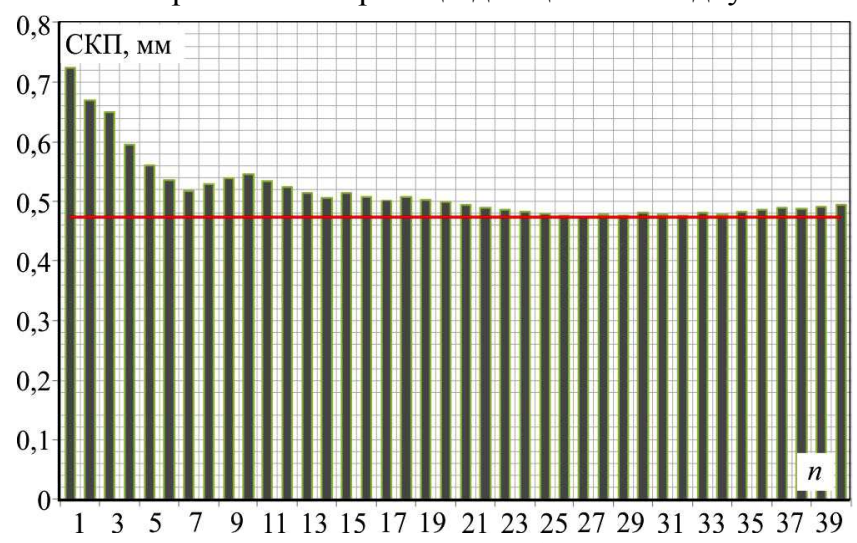

Рис. 2. Залежність впливу кількості вимірювань на СКП
Відповідно до отриманих результатів, що проілюстровані графічно (рис. 2), СКП із збільшенням кількості вимірів зменшувалась. Однак після тридцятого значення $(\mathrm{CКП}=0,472198)$ почала монотонно зростати. У цьому випадку при $n \geq 30$ збільшення кількості виконаних вимірювань $є$ шкідливим 3 погляду забезпечення оптимальної кількості вимірів.

За отриманими результатами можна стверджувати, що повністю позбавитись від систематичних похибок неможливо, деякі систематичні похибки, спричинені незначними змінами умов вимірювання, залишаються. Ця особливість супроводжується незначною кореляцією між виміряними віддалями, що приводить до нагромадження систематичних похибок та погіршення отриманих результатів. Необгрунтоване збільшення кількості вимірювань призводить до розширення часового інтервалу вимірювань та втрати точності шуканого параметра (віддалі).

Визначивши оптимальний розмір вибірки, продовжимо дослідження запропонованої методики розрахунку постійної поправки віддалеміра (v) за даними, отриманими під час експериментальних досліджень на запроектованому створі. На ділянці із бетонним покривом без значних перепадів висот було встановлено два штативи на віддалі 125 м один від одного. Електронний тахеометр та відбивач встановлюють на пунктах 1 та 4 відповідно (рис. 3). Після цього у створі лінії 1-4 на віддалях 41 та 74 м встановлюють штативи у пунктах 2 та 3, у такий спосіб створ розділено на три частини. Кожна віддаль виміряна тридцять разів, оптимальну кількість вимірювань для цього електронного тахеометра було доведено вище. Дослідження виконували зранку у сонячну погоду за температури $14^{\circ} \mathrm{C}$, тиску 737 мм рт. ст.

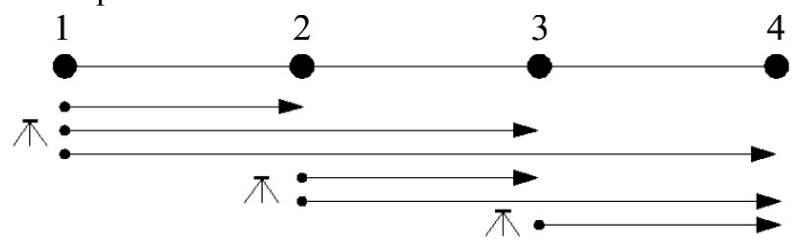

Рис. 3. Типова схема створного способу визначення постійної поправки віддалеміра

Переносячи тахеометр між штативами за наведеною схемою (див. рис. 3) вимірюють всі можливі віддалі:

1) із першої станції вимірюють віддалі: $S_{1-2}, S_{1-3}, S_{1-4}$;

2 ) із другої станції вимірюють віддалі: $S_{2-3}, S_{2-4}$;

3 ) із третьої станції вимірюють віддалі: $S_{3-4}$.

Середні значення виміряних віддалей та їх дисперсії наведено у таблиці.

Таблиця. Результати вимірювань віддалей закладеного створу

\begin{tabular}{|c|c|c|}
\hline & Середня віддаль відрізка, м & СКП, мм \\
\hline$S_{1-2}$ & 41,5434 & 0,0156 \\
\hline$S_{1-3}$ & 74,3465 & 0,0159 \\
\hline$S_{1-4}$ & 125,0361 & 0,0113 \\
\hline$S_{2-3}$ & 32,8 & 0,0069 \\
\hline$S_{2-4}$ & 83,4892 & 0,0132 \\
\hline$S_{3-4}$ & 50,687 & 0,0069 \\
\hline
\end{tabular}

Враховуючи особливості наведеної схеми вимірів (див. рис. 3), можна скласти такі рівняння для визначення поправки: 


$$
\left\{\begin{array}{l}
S_{1-3}^{\text {вим }}-v+S_{3-4}^{\text {вим }}-v-\left(S_{1-4}^{\text {вим }}-v\right)=0 \\
S_{2-4}^{\text {вuм }}-v+S_{1-2}^{\text {вuм }}-v-\left(S_{1-4}^{\text {вuм }}-v\right)=0 \\
S_{1-2}^{\text {вuм }}-v+S_{2-3}^{\text {вuм }}-v+S_{3-4}^{\text {вuм }}-v-\left(S_{1-4}^{\text {вим }}-v\right)=0 \\
S_{1-2}^{\text {вuм }}-v+S_{2-3}^{\text {вuм }}-v-\left(S_{1-3}^{\text {вuм }}-v\right)=0 \\
S_{2-3}^{\text {вuм }}-v+S_{3-4}^{\text {вuм }}-v-\left(S_{2-4}^{\text {вuм }}-v\right)=0
\end{array}\right.
$$

Три перші залежності складено з огляду на те, що суми істинних довжин відрізків лінії, з урахуванням постійної поправки віддалеміра, повинні дорівнювати врівноваженій довжині цілого створу $S_{1-4}$. Дві інші залежності складено за таким самим принципом, однак для проміжних віддалей $S_{1-3}$ та $S_{2-4}$ відповідно. Розв'язавши наведену систему умовних рівнянь, отримаємо значення постійної поправки віддалеміра, апроксимуючі розміри створу та його відрізків, які будуть узгодженими у всіх можливих комбінаціях.

Розроблена методика базується на використанні методу множників Лагранжа під час знаходження розв'язку задачі нелінійного програмування, яка у більшості програмних ресурсів має назву Нелінійний метод узагальненого зведеного градієнта (GRG). Суть цього розв'язку полягає у знаходженні умовного локального екстремуму. При цьому найдоцільнішими є послідовне використання критеріїв мінімізації максимального відхилення та мінімізації повної суми квадратів відхилень (метод найменших квадратів). Метод мінімізації максимального відхилення дає можливість відбракування грубих помилок у виміряних значеннях. Наступна мінімізація повної суми квадратів відхилень (9) дасть змогу мінімізувати випадкові похибки виміряних віддалей, оскільки обрані вибірки піддаються нормальному закону розподілу

$$
\sum_{i=1}^{n}\left(S_{i, j}^{\text {Buм }}-S_{i, j}^{i c m}-v\right)^{2} \rightarrow \min .
$$

Отже, отримаємо найімовірніше значення постійної поправки віддалеміра, значення довжин виміряного створу та його відрізків, які будуть узгодженими у всіх можливих комбінаціях.

Обговорення результатів дослідження. Для адекватної оцінки якості роботи алгоритму, постійну поправку віддалеміра додатково обчислимо відомим методом корелат. Після цього результат, отриманий запропонованим методом нелінійного програмування та відомим методом корелат, підставимо у кожне із рівнянь системи (8). Рис. 4 ілюструє результати розрахунків.

По осі ординат відкладемо залишкову похибку після врахування сталої поправки тахеометра; по осі абсцис порядковий номер рівняння із системи (14). Цифри під гістограмою показують наскільки запропонований метод підвищує точність відносно відомого.

Проаналізувавши дані гістограми, можна стверджувати, що запропоновані технологічні рішення дають змогу підвищити точність урівноваження значення постійної поправки віддалеміра, довжин виміряного створу та його відрізків, порівняно із відомим методом корелат, мінімум на $10 \%$.

Виконаємо оцінку точності отриманих результатів роботи запропонованого алгоритму. Для отримання СКП врівноважених довжин створу та його відрізків виконаємо розрахунок за формулою

$$
m=\sqrt{\frac{\sum_{i=1}^{n}\left(S_{i j}-S_{i k}-S_{k j}\right)^{2}}{n}}=0,6 .
$$

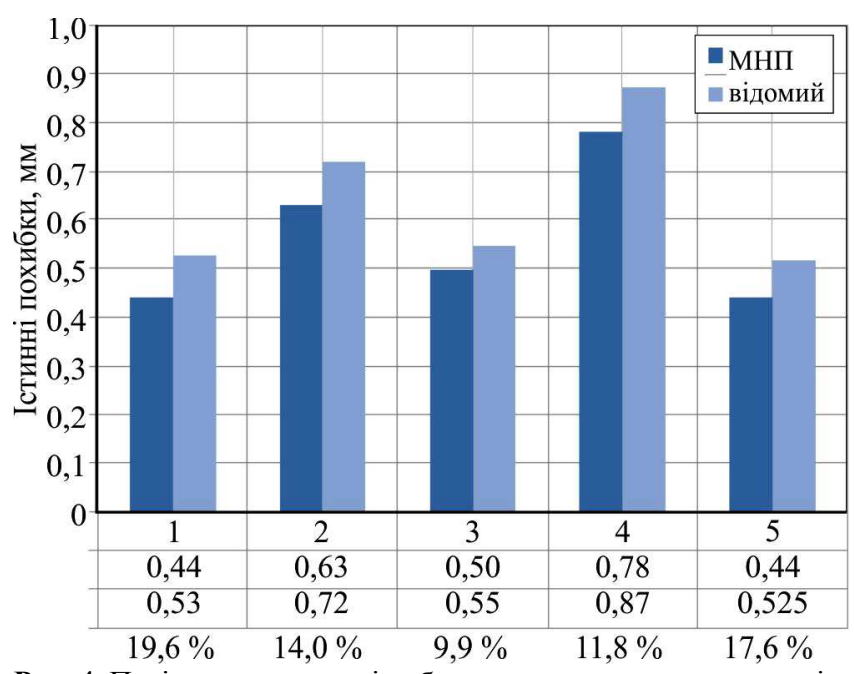

Рис. 4. Порівняння точності роботи запропонованого методу із відомим

Точність врівноважених апроксимованих значень довжини створу і його відрізків практично у три рази вища від задекларованої виробником СКП вимірювання довжин ліній досліджуваного тахеометра SOUTH NTS350.

\section{Висновок}

1. Перевага розробленого алгоритму опрацювання результатів досліджень постійної поправки електронних тахеометрів перед наявними полягає у:

- можливості проводити метрологічний контроль тахеометрів практично на проммайданчику, перед виконанням високоточних інженерно-геодезичних робіт без значних часових та матеріальних витрат порівняно із дослідженнями на еталонному геодезичному полігоні;

- зменшенні часу виконання віддалемірних вимірювань за допомогою визначення оптимальної кількості необхідних вимірювань для приладу, враховуючи вплив кореляційної залежності між величинами інструментальної і випадкової похибок $(\Delta)$;

- відсутності потреби у додаткових дороговартісних приладах.

2. Теоретично обгрунтовано та апробовано алгоритм опрацювання результатів обчислення постійної поправки віддалеміра, вимірюючи довжини створу та його відрізків у всіх комбінаціях. Запропоновано контролювати кількість необхідних вимірювань однієї віддалі опираючись на вплив кореляційної залежності між величинами інструментальної і випадкової похибок. Значення постійної поправки віддалеміра визначено методом не лінійного програмування із послідовним використанням критеріїв мінімізації максимального відхилення та мінімізації повної суми квадратів відхилень (метод найменших квадратів). Водночас, отримане значення постійної поправки віддалеміра $є$ узгодженим із значенням довжин виміряного створу та його відрізків у всіх можливих комбінаціях.

3. Проведено експериментальну апробацію розробленого алгоритму, результати якої підтверджують ефективність використання запропонованих технологічних рішень та показують підвищення точності отриманих результатів мінімум на $10 \%$ порівняно із відомим методом корелат.

4. На прикладі дослідження тахеометра SOUTH NTS-350 показано, що точність врівноважених апроксимованих значень довжин створу і його відрізків прак- 
тично у три рази вища від задекларованої виробником СКП вимірювання довжин ліній.

\section{References}

1. Baran, P. I., \& Baran, P. I. (2012). Inzhenerna heodeziia. Kyiv: PAT "VIPOL", 618 p. [In Ukrainian].

2. Borovyi, V. O., \& Burachek, V. (2017). Vysokotochni inzhenerno-heodezychni vymiriuvannia. Vinnytsia: TOV "Nilan-LTD", 236 p. [In Ukrainian].

3. Braun, J., Dvořáček, F., \& Štroner, M. (2014). Absolute Baseline for Testing of Electronic Distance Meters. Geoinformatics FCE CTU, 12, 28-33.

4. Burak, K. O., Hrynishak, M. Ya., Kovtun, V. M., et al. (2012). Vyznachennia tochnosti vidkhylennia polozhennia blyzkostvornoi tochky za dopomohoiu elektronnoho takheometra. Visnyk heodezii ta kartohrafii, 15-17. [In Ukrainian].

5. Cox, M. G. (2002). The evaluation of key comparison data: An introduction. Metrologia, 39(6), $587 \mathrm{p}$.

6. JCGM 102:2011. (2011). Evaluation of measurement data Supplement 2 to the "Guide to the expression of uncertainty in measurement" Extension to any number of output quantities. Joint Committee for Guides in Metrology. Retrieved from; https:/www.bipm.org/utils/common/documents/jcgm/JCGM_102_2011_E.pdf

7. JCGM 200:2012. (2012). International vocabulary of metrology Basic and general concepts and associated terms (VIM). Joint Committee for Guides in Metrology. Retrieved from; https:/www.bipm.org/utils/common/documents/-jcgm/JCGM_ 2002012 E.pdf

8. Jokela, J., Häkli, P., Kugler, R., Skorpil, H., Matus, M., \& Poutanen, M. (2010). Calibration of the BEV geodetic baseline. In FIG Congress 2(1), 2873-2887.

9. JRP SIB 60. (2021). Metrology for long distance surveying. Retrieved from: http://www.ptb. de/emrp/sib60-home. html
10. Kolomietc, L. V., \& Podostroetc, K. A. (2014). Metrologicheskii kontrol takheometrov. Kompetentnost: nauchno-tekhnicheskii zhurnal, 3(114), 36-40. [In Russian].

11. Kolomiiets, L. V., \& Podostroiets, K. O. (2010). Analiz metrolohichnoho zabezpechennia heodezychnykh zasobiv vymiriuvalnoi tekhniky. Visnyk Inzhenernoi Akademii Ukrainy, 1, 253-255. [In Ukrainian].

12. Kostetska, Ya. M., \& Bletskan, V. (2011). Opratsiuvannia rezultativ doslidzhennia pryladovoi popravky takheometriv za dopomohoiu vymiriuvannia vidrizkiv linii u vsikh kombinatsiiakh. Heodeziia i heodynamika, II (22), 109 -111. [In Ukrainian].

13. Kuzmenko, Yu., \& Samoilenko, O. (2018). Opratsiuvannia za metodom naimenshykh kvadrativ rezultativ vymiriuvan za kliuchovykh, rehionalnykh ta dodatkovykh zviren etaloniv. Metrolohiia ta prylady, 2, 136-143. [In Ukrainian].

14. Litynskyi, V. O., Vivat, A., Perii, S., \& Litynskyi, S. (2015). Cposib vymiriuvannia vzirtsevoho bazysa 2 -ho rozriadu dlia etalonuvannia elektronnykh takheometriv. Heodeziia, kartohrafiia i aerofotoznimannia, 81, 59-65. [In Ukrainian].

15. Podostroiets, K. O., \& Kolomiiets, L. V. (2011). Alternatyvnyi shliakh rozvytku metrolohichnoho zabezpechennia zasobiv vymiriuvalnoi tekhniky dlia vyznachennia velykykh liniinykh rozmiriv. Viiskova osvita i nauka: sohodennia ta maibutnie: tez. dop. VII Mizhnarodnoi nauk.prakt. konf., 24-25 lystopada 2011., Kyiv, VIKNU, 47-48. [In Ukrainian].

16. Tomashevskyi, O. V., \& Rysikov, V. P. (2015). Kompiuterni tekhnolohii statystychnoi obroblennia danykh navch. posib., ZNTU, 175 p. [In Ukrainian].

17. Trevoho, I. S., \& Tsiupak, I. M. (2014). Osoblyvosti metrolohichnoi atestatsii etalonnykh heodezychnykh bazysiv. Suchasni dosiahnennia heodezychnoi nauky ta vyrobnytstva: zb. nauk. prats, 1(27), 29-33. [In Ukrainian].

18. Trevoho, I. S., Denysov, O., Tsiupak, I., Heher, V., \& Tymchuk, V. (2010). Etalonnyi heodezychnyi bazys oryhinalnoi konstruktsii. Suchasni dosiahnennia heodezychnoi nauky $i$ vyrobnytstva, 1(19), 43-49. [In Ukrainian].

B. O. Lysko, V. P. Mykhailyshyn

Ivano-Frankivsk National Technical University of Oil and Gas, Ivano-Frankivsk, Ukraine

\section{DETERMINATION OF CONSTANT CORRECTION OF ELECTRONIC RANGEFINDERS BY NONLINEAR PROGRAMMING METHODS}

The paper deals with the issues of electronic rangefinders correction. In the course of our study an algorithm of research data processing of constant correction of electronic rangefinders has been developed. Its essence is an application of Gaussian method to find the minimum of some function for determining the errors of measured distances. Firstly, the number of required measurements for a device was investigated for consideration of correlation influence between instrumental and random errors. Next, a system of equations is compiled based on relations between the measured target length and its segments in all combinations, taking into account the constant correction of the rangefinder. Thus, conditional equations are obtained with one unknown value - the constant correction of the rangefinder. Due to the large number of measurements, the solution of such system of equations is to find the minimum of some function for determining the errors of the measured distances. In this case, the most appropriate choice is the criterion of minimizing the maximum deviation to reject gross errors of the measured values. Thus, the most probable value of the constant correction of the rangefinder and lengths of the measured target and its segments for all possible combinations has been obtained. The research was carried out on a geodetic landfill under optimal meteorological conditions. The research has also revealed that the proposed technological solutions allow increasing constant correction balancing accuracy of the rangefinder, measured line and its segments lengths in comparison with the known method of correlate by at least $10 \%$. On the example of the SOUTH NTS-350 rangefinder, the accuracy of the obtained approximate values of line lengths and its segments was defined to be almost three times higher than line lengths declared in the technical specifications of the root mean square error measurement for the same device.

Keywords: electronic total rangefinder; measurement errors; minimization of squares of deviations; error theory; equivalent measurements. 